\title{
Internet of Things Enabled Inclusive Business Model for Indian Agriculture
}

\author{
R.Suresh , B.Venkateswara Prasad
}

\begin{abstract}
Indian agriculture need to be revamped due to its low productivity. Indian farmers mostly involved in age-old manual agricultural practices and irrigation systems. farming is highly unorganized and fragmented and the productivity is low, Government subsidies and other support are not sufficient to fulfill the gap. Corporates with their strong financial background can formulate a model with the government support to use smart agricultural devices and its integration with information technology. This paper presents the conceptual model to support the farmers in their agricultural practices to provide better livelihood.
\end{abstract}

Keywords: Productivity, Unorganized, Fragmented, Smart agricultural devices, Information technology.

\section{INTRODUCTION}

The Indian economy has diversified growth in many sectors. Agriculture is one of the core sectors in India. It accounts for $18 \%$ of India's GDP and provides employment opportunities to countries $50 \%$ workforce. India occupies a predominant position in pulses, rice, wheat, spices. Indian agribusiness is as yet confronting the issues, for example, a low level of business sector reconciliation and integration, availability of dependable and convenient information needed by farmers on different issues in farming [1]. The world bank report says "India's food security depends on producing cereal crops, as well as increasing its production of fruits, vegetables and, milk to meet the demands of a growing population with rising incomes. To do so, a productive, competitive, diversified and sustainable agricultural sector will need to emerge at an accelerated pace."[2]. Agricultural productivity to be increased to cater to the demands of the growing population and also to equate the shrinkage of cultivable land. The limited water resource is a major challenge at present and in the future too, the industrial and urban demand for water creates a major challenge for agricultural water resource requirements. Usage of modern automated agricultural practices is required to revolutionize agriculture to increase productivity. Fragmented cultivable land of farmers hinders the usage of automated agricultural practices.

\section{INCLUSIVE BUSINESS MODEL}

The real meaning of inclusive business is not only the decision making of the farmers, but they should also be involved in the marketing of agricultural commodities and other services related to the farming sector. The corporates have huge financial resources, they can redesign products and services rendered to farmers. The corporates can move to the last mile to procure commodities instead of taking them from the dealer. Due to the small scale, farmers have difficulties in approaching financial institutions. The government target to double the income of the farmer by 2022 become possible by modernizing agriculture with an inclusive business model.

\section{APPLICATION OF IOT}

Technologies in agricultural planning and operations can be achieved by using sensors, communications, and analytics. Estimates show that the IoT technology market reached \$130bn in the year 2018. It is estimated that it will reach $\$ 318$ with a compounded annual growth rate of 20 percent

\subsubsection{Transformation of agriculture}

\section{Smart agriculture sensors:}

Sensors used to know the weather conditions, quality of soil crop's growth. These sensors transmit data to the farmer through the cloud. The crop management automation system uses this data for crop management. This automatic crop management operates and controls the irrigation system, maintains soil quality, weed control, pest control, and harvesting.

\section{Quality and yield:}

In order to achieve better control over the cultivation process crop management process needs to be integrated. The integrated crop management process has better control over quality agricultural produce with better yield.

\section{Cost management:}

The usage of smart devices can automate the multiple processes involved in the crop cultivation cycle, processes such as irrigation, fertilizing, or pest control.

The cumulative efforts lead to higher revenue thereby increasing the revenue
Revised Version Manuscript Received on 10, September 2019.

Dr.R.Suresh, Associate Professor, Department of Management Studies, Sri Sai Ram Engineering College, Chennai, Tamil Nadu, India.(Email: suresh.mba@sairam.edu.in)

Dr.B.Venkateswara Prasad, Associate Professor, Department of Management Studies, Sri Sai Ram Engineering College, Chennai, Tamil Nadu, India 


\section{IOT ENABLED MODEL AN OVERVIEW}

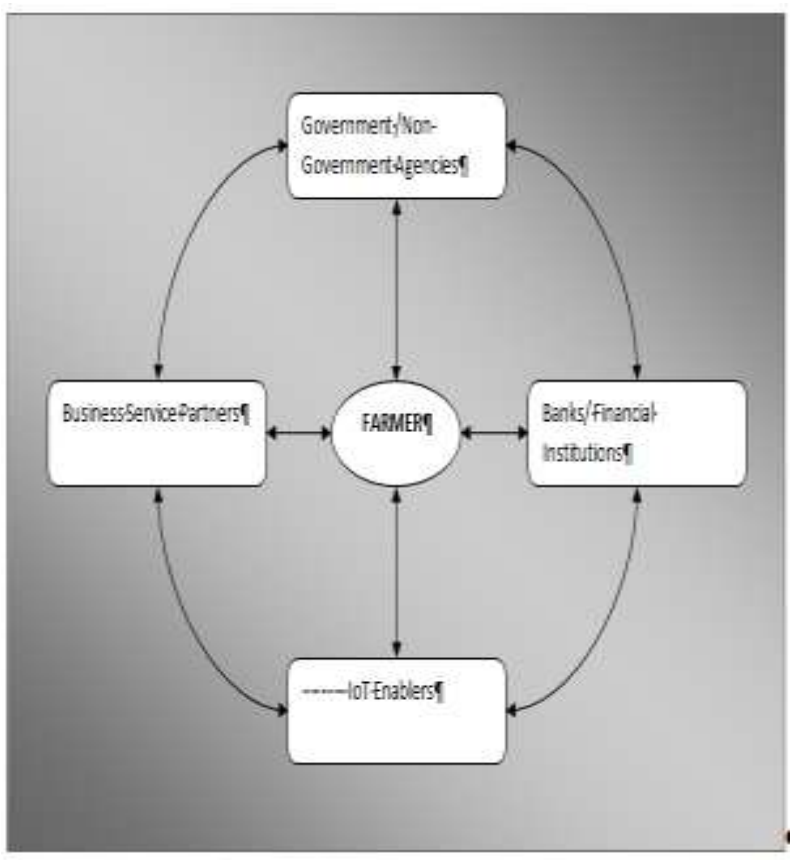

Fig No. 1.1: IoT enabled inclusive Business Model

The general view of the model is given in the above figure 1.1. The model indicates the interactions on four pillars. Business Service partners and the facilitators such as Government /Non-Government Agencies, Banks/ Financial Institutions and IoT enablers. ICT is the backbone of this model, the success of this model depends on support and service rendered by the other facilitators

\subsubsection{Service Model of IoT enabled Agriculture}

The service model of IoT enabled agriculture consist of

- Crop Management

- Price Management

- Government Support

- Financial Institutions Support

- Training for smart devices usage \& Installation

Business service partners play an important role in crop management and related services. Majority of the services offered by them are given in figure 1.2

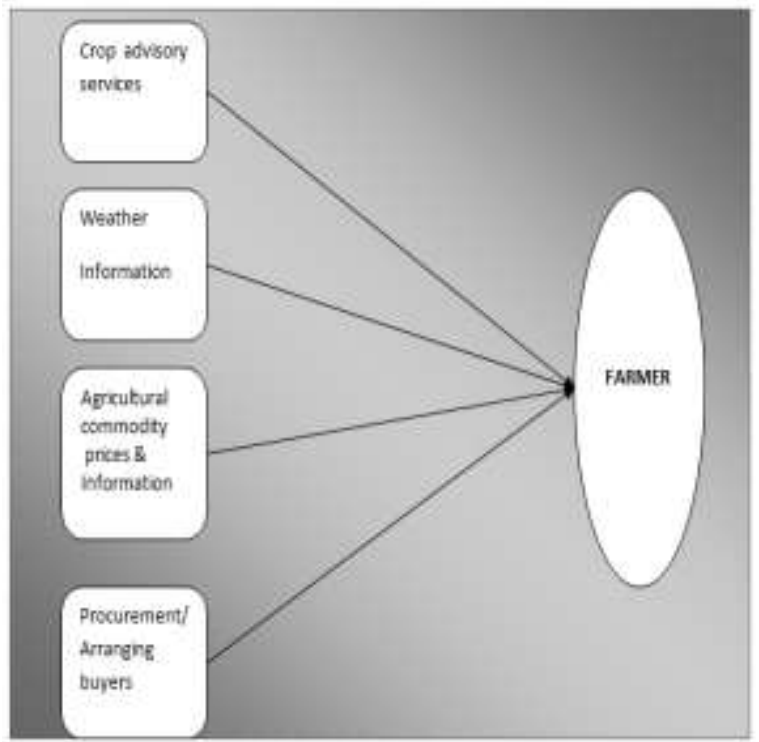

Fig 1.2: Crop management services to the farmers

\section{FEW APPLICATIONS OF IOT IN INCLUSIVE BUSINESS MODEL \& RESULTS}

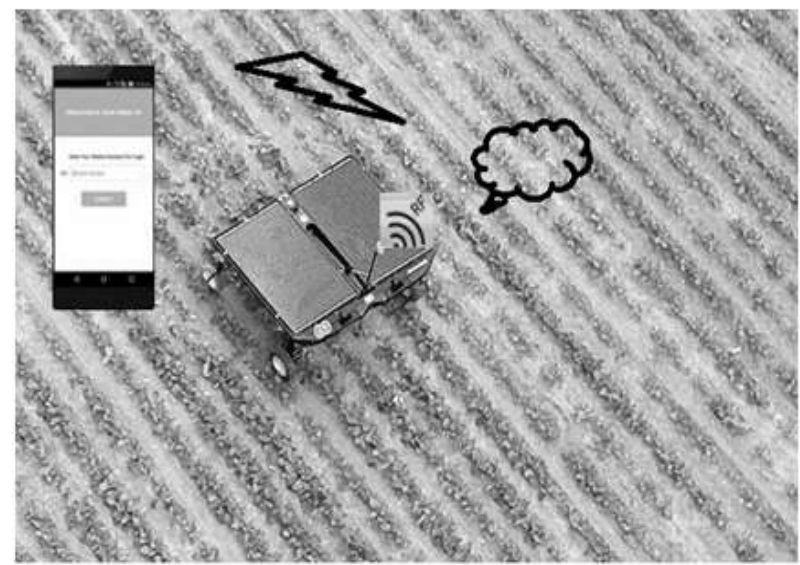

Fig 1.3: IoT enabled Weeding robots

Figure 1.3 shows the working of IoT enabled automatic weeding robots, which sense and remove the weeds and passes the information to farmers through

SMS.

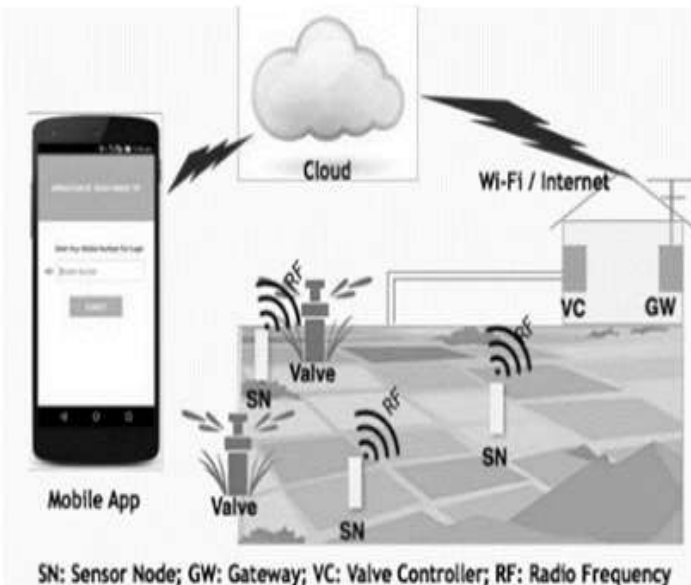

Fig 1.4: IoT based irrigation system

Figure 1.4 shows the IoT enabled sensors and value controller to enable optimum usage of water resources.

\section{CHALLENGES IN THE PROPOSED MODEL}

The success of the proposed model depends on information technology, which is the backbone of this model. The front end driver support is inevitable, the drivers for the success of this model are the enablers. The integration of Business Service partners and the facilitators such as Government /Non-Government Agencies, Banks/ Financial Institutions and IoT enablers. This article proposes only the conceptual aspects. The technical aspects and the feasibility of the model are not discussed, which is beyond the scope of this study. The smart devices were used in most of the developed countries. The smart device technology is not new, but the inclusive business model may bring new challenges due to the new practices adopted in the area of cooperative

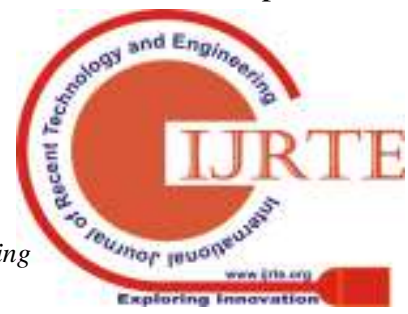


farming and the involvement of corporates. The cost-sharing and the revenue sharing Purely depends on the level of technology used and the nature of crop cultivated

\section{CONCLUSION}

From this study, one can come to the conclusion that how the IoT enabled model can be used in an inclusive business model. The study gives an abstract conceptual outline of the model. The key drivers of the model are farmers, Business Service partners and the facilitators such as Government /Non-Government Agencies, Banks/ Financial Institutions and IoT enablers. The success of the model depends on the farmer's involvement in the understanding of the usage of technology and revenue sharing. It is a win-win situation for both the farmers and business service partners.

\section{REFERENCES}

1. http://www.ccsniam.gov.in/research/KCG\%20Final\%20r eport.pdf

2. https://www.worldbank.org/en/news/feature/2012/05/17/i ndia-agriculture-issues-priorities

3. https://www.worldbank.org/en/topic/financialsector/brief /agriculture-finance

4. https://www.iotforall.com/iot-applications-in-agriculture/

5. Nayyar, Anand \& Puri, Vikram. (2016). Smart farming: IoT based smart sensors agriculture stick for live temperature and moisture monitoring using Arduino, cloud computing \& solar technology, 673-680 